\title{
The Semiology Connotation in the Chinese Ancient Dresses
}

\author{
Juan Yang \\ College of textile and clothing engineering \\ Soochow University \\ Suzhou, China 215123 \\ College of Textile and Clothing Engineering \\ Nantong University \\ Nantong, China 226019
}

\begin{abstract}
China's ancient skirt culture embodies not only the material and cultural value of clothing, but also the thoughts of Chinese traditional philosophy and aesthetics. As a cultural symbol, there is a specific signifier and signified in the skirt, which has a rich symbolic meaning. This artide obtains from the ancient dress symbol, discusses its symbolic language form, and excavates the connotation and implication of symbology from the aspects of traditional philosophy, gender identity construction, fashion and folk customs. And it argues vigorously to understand and acknowledge ancient dress for multi-level and multi-dimensional from the symbology.
\end{abstract}

Keywords-ancient dress; symbology; sexual identity; fashion; folk custom

\section{INTRODUCTION}

As China's important historical resources and cultural artistic treasures, Ancient costumes reflect a certain historical period of politics, economy, culture, science and technology, aesthetic, beliefs, customs and values, etc, with the typical character of the Times. through the clothing we can understand the situation of the society at that time, the humanities environment and the changes of the social consciousness and aesthetic ideas, and so on. Skirts are throughout the history of clothing and still keep in the women's mainstream clothing category. The ancient Chinese skirt has a distinctive symbolic meaning, which not only embodies the material and cultural value of clothing, but also permeates the thoughts of Chinese traditional philosophy and aesthetics.

\section{THE SYMBOLISM OF ANCIENT SKIRT}

As an independent subject, semiology producing in the middle of the 20th century, the founder of the modern semiology, saussure puts forward the concept of semiotics, taking sign as the combination of the signifier and the signified, and pays attention to the language and social function of symbols. "All cultures or civilizations depend on symbols," says 1. a. White, A leading American anthropologist. "There is no culture without symbols, and people are only animals, not humans." [1] Therefore, symbolic form in human development and social civilization, the importance of various cultural phenomena of human are symbolic of the activities, both on the carrier of symbols to express the deep cultural connotation

In terms of the ancient Chinese skirt, there are two levels of meaning. Its visual language of shape, color, decoration and crafts etc. is the direct expression of symbol "signifier". While its content of class status, cultural connotation and ideological implication is the symbol of "signified". The formation and development of ancient Chinese costume cultural symbols was not achieved overnight, but it was influenced by society, politics, economy and culture. Dress changes with the change of dynasties is full of dynamic, through the skirt symbol re lationship between different space, time and occasion, which can effectively grasp the changing rule of the dress, then excavate social function and value of ancient clothing in China civilization of their development.

\section{SYMBOL LANGUAGE FORMS OF ANCIENT DRESS}

\section{A. Font Style of the Phonetic Symbol}

There are two main types of clothing in Chinese dynasties, but in terms of its shape, two main types: the coat with the skirt and the dress. It has been almost three thousand years since the pre-Qin dynasty, the coat with the skirt laid the main status of Chinese clothing, and its importance in the history of Chinese clothing is self-evident. According to Zhou Yi, "the Yellow Emperor... put on the coat and skirt to govern the world, because of the same meaning as the heaven and earth."[2] Therefore, the creation of the coat and the skirt imitates the world, which embodies the awe and worship to the heaven and earth. As the main category of "the down skirt", the dress suit used by both men and wo men to women only in ancient China, has experienced a long history of evolution, with various styles. Ru Skirt, a typical feature is short jacket with long skirt, with the upper and lower proportion full of the aesthetic connotation of golden mean. The skirt gores change with the system and preferences of the dynasties, as shape too, which never get out of the shape pattern of "the coat with the skirt". It embodies female's elegance and the belief of human beings, and is the symbol of the special meaning, which is the 
embodiment of the ancient thought in the form of clothing "Fig. 1".

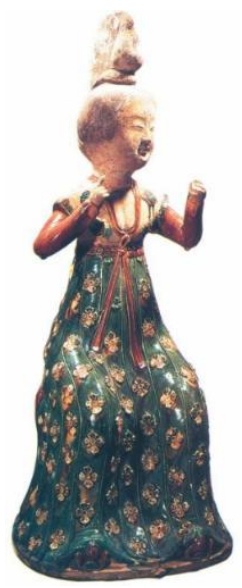

Fig. 1. The making of skirt in the Sui and Tang dynasties.

\section{B. The Color Symbols}

"Making a new calendar, changing colors of clothing" is the symbolic move of ancient Chinese changing dynasties. And the color of clothing has been included in the category of rites since the Zhou dynasty, which has been given the symbolic significance of status. Each dynasty has its own preference color with different color system of clothing. Under the influence of the theory of Yin and Yang, the aesthetic color of Hua Xia is green, red, black, white and yellow, which is used for royalty, formal dress and jacket. Then according to the dialectic principle of the five elements' promotion and restriction, the secondary colors were made, the Rites of Ritual: "The secondary colors would mess the pure colors, which are forbidden to sell on the market." Therefore, the secondary colors different from the honorable pure colors, were mainly used in the clothing, underwear, civilian clothing. As a result, the skirt often uses the secondary color, the color symbol also has certain symbolic meaning according to the characteristic of class or religious belief. For example, Mrs Li in Fairy Set in Yong City praised $\mathrm{Xu}$ Yufu: "The cyan skirt blows the green train." Cyan is widely used in the color of the fairy's clothing. In the ancient immortal belief, "cyan" often condensed the cultural factors of wonder and mystery, and became a deification of the colors and visual semantics and construction of the deities. In line with the religious culture of Taoism, which embodies the natural, feminine, quiet and implicit beauty of Taoism, is the meaning symbolic expression of Taoist women's fairy dress.

\section{Decorative Symbols}

The decoration of ancient skirts was mainly divided into patterns, design and decorative techniques. There doesn't need to say about patterns and design, which develop from the symbolic characteristics of the traditional Chinese costume patterns, extremely full of lucky. Their main themes are auspicious animals, lucky artifacts and flower-and-bird insect fish containing good wish, composing patterns, designs in the form of dot, line, face, body, arranging mainly by scattered point, circulating, continuous, etc. Also pure surface is given priority to, design with the skirt or dress Lan, or hidden in furbelow. Adornment craft is more unending, such as jacquard, makeup flower, embroidery, calligraphy and painting, plait, pile of gauze, fall object and so on. The ancient dress forms a certain aesthetic symbol through various decoration techniques, which becomes the carrier of the meaning of the dress, and also embodies the common characteristics of the ancient costume aesthetics system.

\section{THE CONNOTATION EXPRESSION OF DRESS CULTURAL SYMBOLS}

\section{A. The Expression of Traditional Philosophy Thought}

Whether the ancient Chinese skirt in traditional form system of "the coat with the skirt" according to the worship of heaven and earth, or auspicious blessings decorated on the skirts through artistic polishing, or the time features reflected by the changing of the colors of clothing, all of them reflect the ancient classical philosophy thoughts, "Unity of Nature and Humanity", "Interaction of Heaven and Man" and "The Scenery Serve for the Mood". Through the dress cultural symbol lining the natural order and social order, and through the system and image of clothing, it reflects the people's life view and world view, full of cultural connotation and historical value, and has far-reaching influence on later generations.

\section{B. The Formation of Gender Identity}

Masculine and feminine, as a gender term, refer to appropriate, masculine or feminine ways of thinking, behavior and feeling in a society.[5] Clothing, as an important carrier of social change and culture, is often associated with gender to become the symbol of gender. The Chinese word "Qun" appeared in the Han dynasty, was composed of two pieces of the front and back "stripping". Although there are also a few phenomenon men in the skirt in the history of ancient China, in the long history of clothing changing, under the skirt is the ancient Chinese women's main clothing, which can be served as a sex symbol of ancient Chinese women [6].

In ancient China, in addition to distinguish gender through the clothing, also through a series of ritual and specifications to construct the gender differences in status, especially the Confucian values of "male superiority to female" embodied in the ancient Chinese clothing. The phenomenon of women's foot-binding in ancient times fully explained the subordination of wo men to men and the feudal concept of restricting women's behavior. For the skirt, the supporting decoration "forbidden step" is a good example. "The forbidden step" is a kind of feminine dress in the Ming dynasty, which is a combination of jade ornaments and ribbons, hung on both sides of the waist to hold the hem on the skirt "Fig. 2". When walking, the sounds of jade decorations are considered as impolite. This persuasion influence of strengthening the "woman virtuous", embody the gender identity construction of the dress symbol. 


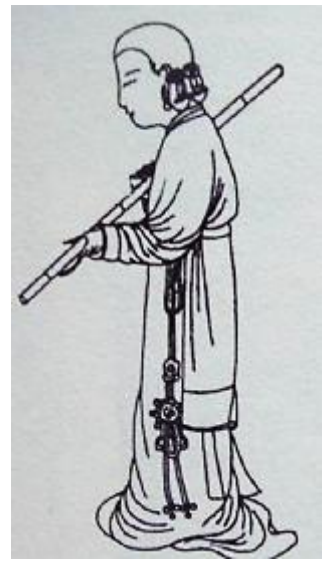

Fig. 2. "The forbidden step" in the pint Yushirenfeng in the Ming Dynasty.

\section{The Reflection on Fashionable Trends}

Fashion is not a modern word. It has existed since the beginning of human civilization. Although fashion is not the "master key" to understand the modern world, it is an important way to understand the world [7]. Dresses present a different aesthetic fashion in different historical periods. A particular period of the political system, economy and technology development, social events, and even individuals of aesthetic interest are likely to influence the fashion trends. For example, the Han dynasty advocated the "boundless skirt" without decoration and edge; during the period of Wei and Jin dynasties, style, color and adornment is increasingly abundant, at this time, "the secondary color skirt" interval by the cloth of more than two colors became fashionable. During the Sui and Tang dynasties, in the open social environment and the unprecedented prosperity of economic and technological conditions, the style and gore of the skirt has been to the peak, with six, eight and twelve gores, reputed as "fairy dress". At that time, the most representative is princess Anle's "wool bird skirt". According to the New Tang Book, "princess Anle let others collect birds' feathers to make a wool bird skirt, showing one color in front and the other color from the side, showing one color in the day, the other color in the shadow with all feathers appearing." [8] The dress was particularly popular at the time, with royal women following it, which led to the killing rare birds at one point and was finally banned under the interference of the court. Thus it can be seen that skirt symbol is not only a reflection of social phenomena in a particular historical environment, but also an interpretation of the prevailing fashion.

\section{The Refraction to Popular Customs and Folkways}

Through the traditional skirts of visual symbols, not only can see its cultural meaning and popular fashion, to a certain extent, but also can reflect the various historical periods of folk customs. It has a direct meaning for understanding the situation of the society people's production and life style and living condition at that time. For example, the Ming and Qing dynasties, women made their own personal dresses, which were enshrined in the temple, as their incarnation. The dress also could be a gift to friends and relatives, even with poems painted on it. In the Ming dynasty, there was also the custom of skirts competition. The famous lady Dong Xiaowan, good at drawing, once competed in painting a dress with the others. In addition, ancient women would wash their skirts on the water side during the first lunar month to avoid disaster and seek peace, which is the ancient custom of "Jian Qun".

\section{CONCLUSION}

The symbol information carried by Chinese ancient skirts in the historical development is not a simple visual representation, but spiritual beliefs and a reflection of social change, customs. It expresses the people to the world, life, religion, value, etc, which is an important part of Chinese traditional culture. It is through the common representation of the visual symbol and the object to achieve the high unification of practical and aesthetic, art and technology.

\section{REFERENCES}

[1] America. Leslie A White. The science of culture —researches on human beings and civilization [M].Jinan: Shandong people's publishing house, 1988:21,33.

[2] Huang Shouqi, Zhang Shanwen. Translation and annotation of the book of changes $[\mathrm{M}]$.Shanghai: Shanghai Chinese ClassicsPublishing House, 2012:344.

[3] [Tang Dynasty]Du Guangting. The biography of immortals in Yong city (the Taoist patrology), volume 18). Beijing: Beijing cultural relics publishing house, 1998:176.

[4] Tian Xiaoying. The cultural connotation of green and purple design signals on the fairy's clothes in Yong city[J]. Religious Studies,2013(2):70-73.

[5] [Britain] Elaine Baldwin, etc., translated by Tao Dongfeng. Introducing Cultural Studies.Beijing: Higher Education Press, 2004(7):286

[6] Luo Wei. Researches on ancient female clothes of the Han ethics[D]. Minzu University of China,2003.

[7] [Norway] LarsSvendsen, translated by Li Man. The Philosophy of Fashion [M].Beijing: Peking University Press,2010(1):3.

[8] Wang Jixun. The Development and Evolution of Female Skirts in Chinese History [J].Journals of Shandong women's University,1997(4):32-35.

[9] Ma Dayong. Ancient dresses of Chinese females [M]. Chongqing: Chongqing University Press,2011(3):257. 